\title{
Traumatic Loss and Major Disasters: Strengthening Family and Community Resilience
}

FROMA WALSH, PH.D. $\dagger$

This article presents the core principles and value of a family and community resilience-oriented approach to recovery from traumatic loss when catastrophic events occur. In contrast to individually based, symptom-focused approaches to trauma recovery, this multisystemic practice approach contextualizes the distress in the traumatic experience and taps strengths and resources in relational networks to foster healing and posttraumatic growth. The intertwining of trauma and traumatic losses is discussed. Key family and social processes in risk and resilience in traumatic loss situations are outlined. Case illustrations, model programs, and intervention guidelines are described in situations of community violence and major disasters to suggest ways to foster family and community resilience.

Keywords: Family and Community Resilience; Traumatic Loss; Disaster Recovery

Fam Proc 46:207-227, 2007

$\mathrm{T}$ The word trauma comes from the Latin word for wound. With traumatic experiences, the body, mind, spirit, and relationships with others can be wounded. The predominant therapeutic models used for treating trauma and survivors of major disaster have been individually focused and pathology based, centered on identifying and reducing symptoms of posttraumatic stress disorder (PTSD), categorized as a mental disorder. (See the DSM III \& IV, American Psychiatric Association, 2000, and the ISCD, World Health Organization, 1972.) In contrast, a multisystemic, resilience-oriented practice approach recognizes the widespread impact of major trauma, situates the distress in the extreme experience, attends to ripple effects through relational networks, and aims to strengthen family and community resources for optimal recovery.

\section{FROM INDIVIDUALTO MULTISYSTEMIC APPROACHES IN TRAUMA RECOVERY AND RESILIENCE}

Groundbreaking studies of World War II and Vietnam veterans and their families (e.g., Catherall, 1992; Figley \& McCubbin, 1983; Hill, 1949) revealed the stressful

\footnotetext{
$\dagger$ Mose and Sylvia Firestone Professor, School of Social Service Administration and Department of Psychiatry; and codirector, Center for Family Health, University of Chicago.

Correspondence concerning this article should be addressed to Froma Walsh, 969 E. 60th Street, Chicago, Illinois 60637. E-mail: fwalsh@uchicago.edu
} 
effects of combat experience on family systems. Yet, in the individually focused field of traumatology, only a few, led by Figley, have addressed the impact in relational systems wrought by war, catastrophic events, and widespread disaster (Catherall, 2004; Denborough, 2006; Webb, 2003). Serious individual and relational distress can occur with anxiety, depression, substance abuse, violence, and estrangement. Loved ones often suffer from secondary traumatization and compassion fatigue (Figley, 2002) in learning about, and responding empathically to, a loved one's trauma experiences, and also through ongoing contact when disruptive symptoms and harmful behaviors persist. Entire families can experience primary effects of mass trauma. Family functioning and vital kin networks can be disrupted, especially with complex, ongoing, or recurrent trauma, as experienced by those living in war or conflict zones. Therefore, attention to the family impact of major trauma is essential in any treatment approach. Moreover, family and community networks can be essential resources in trauma recovery when their strengths and potential are mobilized.

Traumatic stress investigators, although individually focused, are increasingly interested in understanding resilience (see proceedings, "The Psychobiology of Trauma and Resilience Across the Lifespan," 22nd Annual Meeting, International Society for Traumatic Stress Studies, 2006). Studies find that acute stress symptoms are very commonly experienced immediately after extreme trauma situations. However, most individuals are resilient in coping and adaptation, rebounding within several months, and do not suffer long-term disturbance (Litz, 2004; McFarlane, 1996). Moreover, many studies find that the suffering and struggle to recover in the aftermath of a traumatic experience often yields remarkable transformation and positive growth. Studies of posttraumatic growth (Tedeschi \& Calhoun, 1996) have found positive individual changes in five areas: (1) emergence of new opportunities and possibilities; (2) deeper relationships and greater compassion for others; (3) feeling strengthened to meet future life challenges; (4) reordered priorities and fuller appreciation of life; and (5) deepening spirituality (Calhoun \& Tedeschi, 1999, 2006).

Van der Kolk and colleagues have advanced a bio-psycho-social understanding of trauma, its treatment, and its prevention, including attention to variables that influence vulnerability, resilience, and the course of posttraumatic recovery (van der Kolk, McFarlane, \& Weisaeth, 1996). Although some individuals are more vulnerable to stress, no one is immune to suffering in extreme situations. Studies have found that the effects of trauma depend greatly on whether those wounded can seek comfort, reassurance, and safety with others. Strong connections, with trust that others will be there for them when needed, counteract feelings of insecurity, helplessness, and meaninglessness. Times of great tragedy can bring out the best in the human spirit: ordinary people show extraordinary courage, compassion, and generosity in helping kin, neighbors, and strangers to recover and rebuild lives.

Mental health professionals can best foster trauma recovery by shifting from a pathology focus and expanding the predominant individual treatment approaches to mobilize this capacity for healing and resilience in families and communities (Rutter, 1999; Walsh, 2003, 2006). A multisystemic resilience-oriented approach contextualizes the distress, addresses the family impact, and strengthens interpersonal and institutional resources for both individual and collective recovery and posttraumatic growth. 


\section{Traumatic Loss}

In the trauma and bereavement fields, there is increasing recognition of the intertwining of trauma, loss, and grief (Figley, 1998; Lattanzi-Licht \& Doka, 2003; Litz, 2004; Neimeyer, 2001). Deaths that are untimely, sudden, and/or violent are the most common source of trauma (Norris, 2002). Trauma situations may involve physical illness, harm, or disability; abduction, torture, incarceration, or persecution; relationship dissolution; job loss; migration/relocation; violence; and/or sexual abuse. Traumatic losses posing high risk for complicated recovery, as summarized in Table 1, require careful assessment and intervention focus.

Various forms of trauma experienced in catastrophic events can involve multiple losses, including the following:

- sense of physical or psychological wholeness (e.g., with serious bodily harm);

- significant persons, roles, and relationships;

- head of family or community leader;

- intact family unit, homes, or communities;

- way of life and economic livelihood;

- future potential (e.g., with the loss of children);

- hopes and dreams for all that might have been;

- shattered assumptions in core worldview (e.g. loss of security, predictability, or trust).

It is essential to assess and address complicated losses as an essential aspect in trauma recovery.

TABLE 1

Situations of Traumatic Death and Loss

The meaning and impact of traumatic deaths are influenced by a number of variables in the loss situation that require careful assessment and attention.

Violent death. A violent death is devastating for loved ones and for those who witnessed it or narrowly survived. Preoccupation with causal accusations, guilt, or wishes for retaliation is common. A senseless tragedy, loss of innocent lives, and deliberate acts of violence are especially hard to bear.

Untimely death. Untimely losses are hardest to bear. The death of a child or young spouse seems unjust and robs future hopes and dreams. The loss of parents with young children requires reorganization of the family system.

Sudden death. Sudden losses shatter a sense of normalcy and predictability. Shock, intense emotions, disorganization, and confusion are common in the immediate aftermath. Loved ones, unable even to say their goodbyes, may need help with painful regrets.

Prolonged suffering. Prolonged physical or emotional suffering before death (e.g., with assault, torture, or lack of medical care) increases family agony, as well as anger or remorse.

Ambiguous loss. Unclarity about the fate of a missing loved one can immobilize families who may be torn apart, hoping for the best yet fearing the worst (Boss, 1999). Mourning may be blocked until remains or personal effects are recovered. Families may need help in pressing for information and in resuming lives in the face of lingering uncertainty.

Unacknowledged, stigmatized losses. Mourning is complicated when losses or their causes are disenfranchised (Doka, 2002), hidden because of social stigma (e.g., HIV/AIDS) or collaboration with the enemy. Secrecy, misinformation, and estrangement impede family and social support.

Pile-up effects. Families can be overwhelmed by the emotional, relational, and functional impact of multiple deaths, prolonged or recurrent trauma, and other losses (homes, jobs, communities) and disruptive transitions (separations, migration).

Past traumatic experience. Past trauma or losses, reactivated in life-threatening or loss situations, intensify the impact and complicate recovery. 
In traumatic loss, symptoms such as depression, anxiety, substance abuse, and relational conflict and cut-off are common. Survivors blocked from healing may perpetuate suffering through self-destructive behavior or revenge and harm toward others. Massive trauma or loss of hope and positive vision can fuel transmission of negative intergenerational patterns (Danieli, 1985), affecting those not yet born. With murder, atrocities, and injustice, the impetus for retaliation to restore a sense of family or community honor can lead to cycles of mutual destruction.

When traumatic loss is suffered, we should not expect resolution in the sense of some complete, "once-and-for-all" getting over it. Thus, resilience should not be seen as readily getting "closure" on the experience or simply bouncing back and moving on. Recovery is a gradual process over time. Various facets of grief may alternate and reemerge with unexpected intensity, particularly with anniversaries and other nodal events (Rando, 1993). Attention commonly oscillates between preoccupation with grief and reengagement in a world forever transformed by loss (Stroebe \& Schut, 2001).

In traditional psychiatric approaches to grief work, mourning was thought to require letting go of lost attachments. Bereavement specialists now view adaptive mourning as best facilitated through transforming losses to continuing bonds in spiritual connections, memories, deeds, and stories that are passed on across the generations (Neimeyer, 2001; Walsh \& McGoldrick, 2004). Coming to terms with traumatic loss involves making meaning of the trauma experience, putting it in perspective, and weaving the experience of loss and recovery into the fabric of individual and collective identity and life passage.

\section{Facilitating Family and Community Adaptation to Trauma and Loss}

To foster recovery from major traumatic events, we can usefully apply the four tasks in adaptation to loss identified by Walsh and McGoldrick (2004). Helping professionals can facilitate healing and resilience by encouraging individuals, families, and communities to actively engage in the following processes:

1. Shared acknowledgment of reality of traumatic event, losses

Clarification of facts, circumstances, ambiguities

2. Shared experience of loss and survivorship

Active participation in memorial rituals, tributes, rites of passage

Shared meaning making; emotional expression; spirituality

3. Reorganization of family and community: Planning for survivors' well-being

Restabilization to foster continuity and change

Realignment of relationships; reallocation of roles, functions

Rebuilding of lives, homes, livelihood, kinship, and community

4. Reinvestment in relationships and life pursuits

Constructing new hopes and dreams; revising life plans, aspirations

Finding new purpose from the tragic loss and the spirit of loved one(s) lost 
Pathways in mourning and adaptation vary with personal, family, cultural, and religious preferences (Wortman \& Silver, 1989). Families may need help to develop tolerance for different coping styles, decisions, and pacing of grief processes among members. Community and multifamily interventions also need to foster openness and respect for differences.

\section{Family and Social Processes in Risk and Resilience With Traumatic Loss}

In helping families and communities in response to traumatic loss, we can draw usefully on the framework for family resilience described in earlier work (Walsh, 2003, 2006). Attention to the following belief systems, organizational patterns, and communication processes can reduce vulnerability and risk and can foster resilience in recovery from traumatic loss (Table 2).

Belief Systems. It is crucial to understand each family's belief system, rooted in cultural and spiritual traditions, which influences members' perceptions and coping responses to traumatic experiences. Clinicians can facilitate the following processes, which fit well with the posttraumatic growth areas found by Calhoun and Tedeschi (2006).

Making meaning of traumatic loss experience. Initially it is important to contextualize members' distress as understandable and common among those who have experienced similar tragedies. Resilience is fostered as we help family members gain a sense of coherence, rendering their trauma experience more comprehensible, meaningful, and manageable as a shared challenge. After a tornado destroyed their home and business, the father in one family recounted to a counselor, "At first we were in a state of shock and disoriented, at a total loss about what to do. Then we dusted ourselves off, took stock of our predicament, and took charge to clear out the debris and figure out our options. We just kept hugging each other and taking it step by step."

Family members may struggle over a period of time to make sense of what happened, gain perspective, and make it more bearable (Nadeau, 2001). Shattered assumptions in their basic worldview can be a profound symbolic loss (Janoff-Bulman, 1992; Kauffman, 2002). Certain core beliefs ground and orient people, providing a sense of reality, meaning, or purpose to life. Assumptions may be that others can be trusted; that communities are safe; that there is a predictable future; that children outlive their elders; that God is just. When such assumptions are shattered by a sudden, unexpected catastrophic event, there is a deep need to restore order, meaning, and purpose. Meaning reconstruction in response to trauma and loss is a central process in healing (Neimeyer, 2001). It can reflect a new kind of wisdom born of experience and a testament to survivors' strengths. In recovery work, we may need to help people reconstruct a new sense of normality, identity, and relatedness to adapt to altered conditions. We cannot make meaning for them; our task is to support their efforts in finding their own meaning out of their experience (Frankl, 1946/1984).

Commonly, families grapple with painful questions such as: Why us? Why my child and not me? How could this have happened? Who is to blame? Was it accidental or deliberate? Could it have been prevented? Such concerns persist when, for instance, the cause of a plane crash remains unclear. Clinicians can help families gain factual information and examine beliefs that foster blame, shame, and guilt. It is important to help family and community members share concerns about responsibility or 

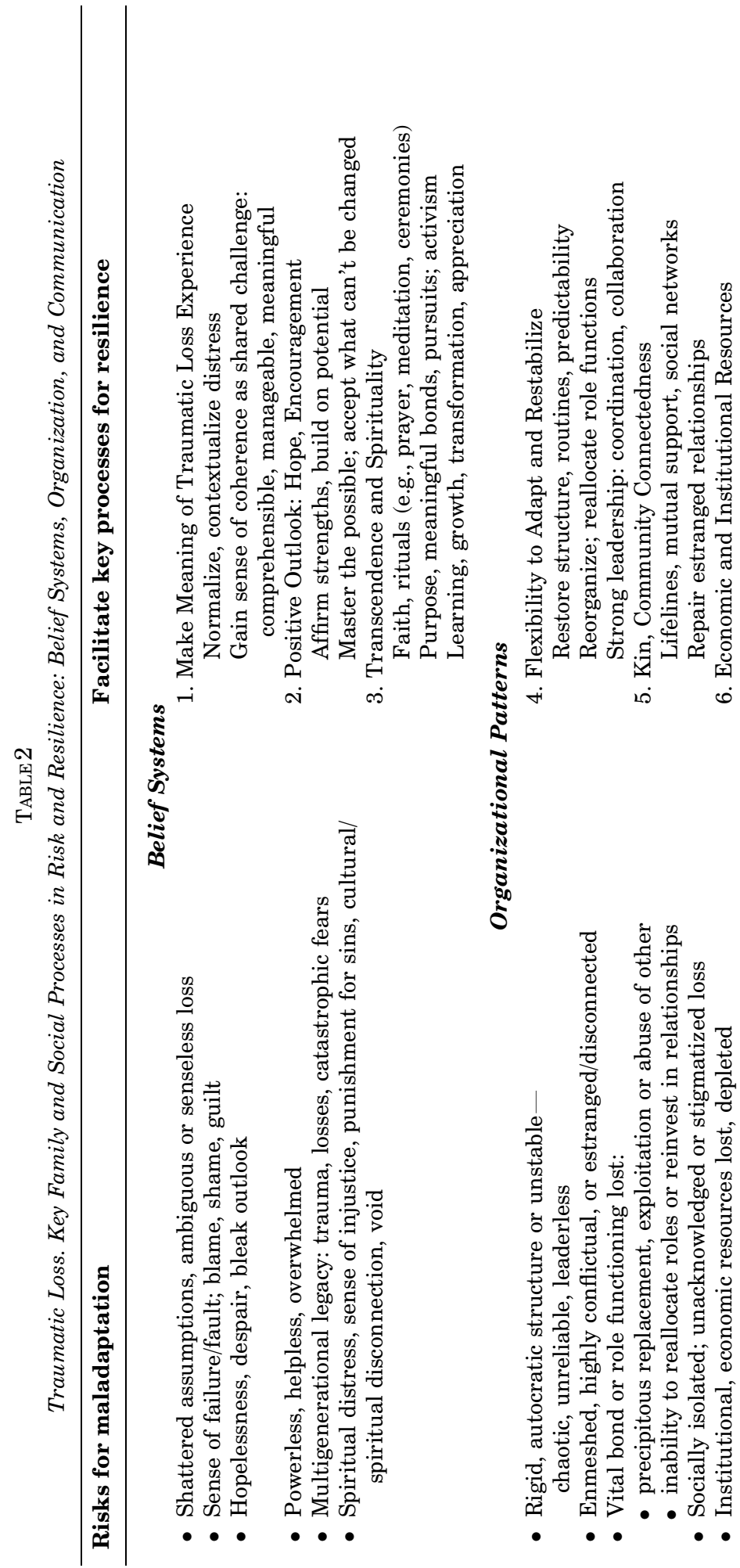

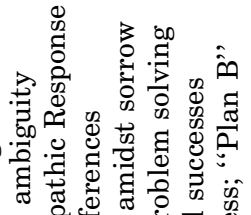

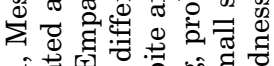

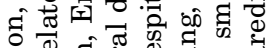

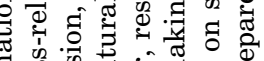

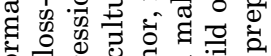
速范 द्व क्ष त्र

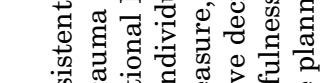

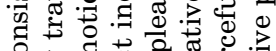

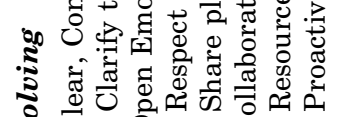

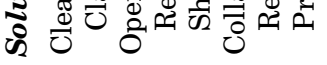

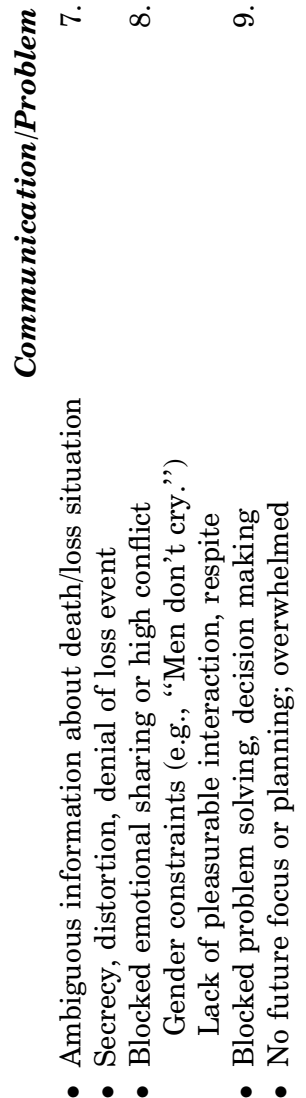


negligence, come to terms with accountability and limits of control in the situation, and take lessons from the experience to guide future action.

Hope: A positive outlook. In times of deepest despair, hope is most essential for recovery. Hope fuels energies and investment to rebuild lives, revise dreams, renew attachments, and create positive legacies to pass on to future generations. Resilience involves "mastering the possible," coming to accept what has been lost and cannot be changed, while directing efforts to what can be done and seizing opportunities for something good to come out of the tragedy. In the wake of devastating trauma, we can help families regain hope in their future possibilities.

Transcendence and spirituality. With traumatic loss, transcendent cultural and spiritual values and practices can provide meaning and purpose (Walsh, 2004). Many find solace in the belief that catastrophic events may be beyond human comprehension but a test of faith or part of God's larger plan. Prayer, meditative practices, and faith communities can provide strength and support. In human-caused tragedies, faith beliefs open a pathway of forgiveness for many (Walsh, 2006; Worthington \& Scherer, 2004). Spiritual connection, memories, stories, and deeds can honor the best aspects of those who died, all that was lost, and the courage and resilience forged. Participation in memorial rituals, vigils, anniversary remembrances, rites of passage, and celebrations of milestones in recovery all facilitate healing and growth. They also provide opportunities to reaffirm identity, relatedness, and core social values of goodness and compassion (Imber-Black, Roberts, \& Whiting, 2003). Finding ways to celebrate holidays and birthdays, which often go unmarked in the midst of turmoil and grief, can boost spirits and reconnect all with the rhythms of life.

Suffering can be transcended in creative and symbolic expression through the arts. Music, such as participation in community or congregational singing, can release sorrow and be uplifting, restoring spirits to carry on. Finding ways to express the experience of trauma and survival through writing and artwork can facilitate resilience.

Healing is aided through dedications to honor those who were lost. Many find new purpose and transformation through community activism or advocacy to benefit others and prevent future suffering (Perry \& Rolland, 1999). Learning and growthful change out of tragic loss can spark new and renewed commitments and priorities. Recovery is a journey of the heart and spirit, bringing survivors back to the fullness of life.

\section{Organization}

Flexibility and stability. For resilience, families and communities must effectively organize to respond to traumatic events. Flexibility is needed to reallocate roles and adapt to changed conditions and unforeseen challenges. At the same time, to reduce the sense of chaos and disorientation that occurs with disruption and transitional upheaval, it is crucial to restore order, safety, and stability. Children especially find reassurance as daily routines can be resumed or new arrangements put in place. Strong leadership and coordination of response efforts is essential, with collaboration between families and social networks. In major disasters, community groups, agencies, and all government levels involved in rescue, recovery, and reconstruction efforts must have clear plans, lines of authority, and communication. With the loss of basic infrastructure, family and social systems must reorganize, recalibrate, and reallocate roles and functions. Clear rules and guidelines must be established and followed through consistently. 
Connectedness. With traumatic loss experiences, helplessness and terror are common. Individuals, especially children, have an urgent need to know that they can count on others for support, comfort, and safety. Although high cohesion is essential, family members need tolerance and respect for individual differences in crisis response. Some may show anxious clinging or need to be in constant contact with loved ones; others may avoid the pain or loss by distancing. In chaotic situations or evacuations, every effort should be made to keep family members together, so they are not left to fend for themselves, isolated in their suffering, and worried about others. In forced separations, contact information and communication ease worries and facilitate reunion. When trauma has involved a violation in human connection - for instance, in harm by a family member, friend, or neighbor - trust and security are more difficult to restore. If relationships were troubled or estranged, distress is intensified by unresolved conflicts. Family therapy can be helpful in fostering relational healing, reconnection, and reconciliation.

Extended kin, social, and economic resources. With major trauma and loss, it is crucial to mobilize institutional services as well as kin, social, and community networks for emotional and practical support (Imber-Black, 1988; Speck, 2003). Involvement of extended social systems might include friends, neighbors, health care providers; clergy and congregational support; school teachers and counselors; employers and coworkers; and neighborhood or community organizations. Multifamily community support groups are ideal contexts for exchanging information, sharing painful memories and feelings, providing mutual support, and encouraging hope and efforts for recovery. Financial assistance is also critical with the loss of homes and jobs, medical expenses, or rebuilding costs.

\section{Open Communication}

Clear, consistent information. Families often need help to clarify facts and circumstances of traumatic events, particularly in cases of ambiguous loss (Boss, 1999). Practical guidelines assist them in rebuilding their lives. To avert confusion in mass trauma situations, those in charge of emergency and recovery plans must provide clear, consistent, and accurate information. When errors or changes occur, swift update of information reduces frustration. When ambiguity persists, as in the fate of a loved one who is missing or wounded, families need help in living with uncertainty while sustaining hope.

Emotional sharing and support. Traumatic loss can trigger a wide range of intense feelings - rage, fear, sorrow, guilt - among survivors, with ripple effects throughout kin and community networks. When painful or unacceptable feelings can't be expressed and supported, or when differences are viewed as disloyal or threatening, there is a higher risk of somatic and emotional disturbance, destructive behavior, and substance abuse. It is important to foster a climate of mutual trust, empathic response, and tolerance for a wide range and fluctuation of emotions over time.

Collaborative problem solving. Practical assistance with immediate needs is essential. Goals should be concretized in realistic steps, tasks, and projects. Over time, with the slow pace of recovery and rebuilding of lives, it is important to rally family and community collaborative efforts to experience small gains and celebrate progress. Above all, it is crucial to learn from a trauma experience in order to be proactive to meet future threats. It is essential to shift from a crisis-reactive mode to preparedness 
planning to lower future risks and mobilize responses that, if needed, will build connection, reduce suffering, and strengthen resilience.

\section{TRAUMATIC LOSS IN COMMUNITY VIOLENCE}

Every day, violence takes place in our communities and in our larger social world. As Weingarten (2003) noted, it can become a common shock, barely arousing us until our lives or those important to us are directly affected. In neighborhoods blighted by chronic conditions of poverty, discrimination, and violence, daily life for children and families is much like living in a war zone (Garbarino, 1997). Each violent incident is a tragedy for the families it touches. As the following case demonstrates, small actions taken by families and communities, facilitated by helping professionals, can promote healing and resilience.

A shooting death near my own neighborhood began with an escalation of taunts between White and Latino youths, which turned lethal. With the catalyzing influence of a parish priest and his congregation, and with the courageous efforts of the parents of the boy who was killed, a remarkable journey of recovery, transcendence, and transformation took place over the following year (Shefsky, 2000; Terkel, 2002).

When Mario, an 18-year old Latino gang member, was charged with the shooting, his priest told his congregation, "He is a son of our parish; we must reach out to him and his family and offer our prayers and assistance." He visited the Ramos family, hardworking, caring Mexican immigrants who were in deep pain and struggling to comprehend their son's violent act. The priest visited Mario in detention and encouraged parishioners to write to him and also to pray for the Young family, whose son he had killed. Although the Youngs were not members of his parish, he extended himself, going to their home to offer condolences and to let them know he was there for them if there was any way he could be of assistance. Andrew's father, who wasn't home at the time, was at first angered by the visit: "This was his kid who killed our son!" But a few nights later, unable to sleep, he called the priest after midnight and they talked for over an hour. The priest's outreach and compassion led the parents to attend parish services, where they found solace in the caring community.

Over several months, the faith community's outreach to Mario fostered a genuine transformation; he left the gang, affiliated himself with a Christian group for support, and wrote a letter to Mrs. Young to express his deep remorse for the killing and to ask for her forgiveness. "There's no way I can bring back your son; I only hope that something good can come out of this."

Mrs. Young's own deep faith led her to write to Mario to offer compassion and forgiveness. As she later explained, she came to this decision to heal from the tragedy and to be better able to help her family in their unbearable suffering. Her husband hadn't been able to work for months, their surviving children were devastated, and the youngest son had run into traffic hoping to be hit so he could join his big brother in heaven. She understood her husband's deep anger, and the common human impulse for revenge that some were expressing, but she spoke out against any retaliation. She said she felt she would lose her mind if she didn't try to draw something positive out of the tragedy. She found inspiration from her childhood religious upbringing, recalling from the bible that unforgiveness corrodes the mind, the body, and the spirit. In offering forgiveness, she clearly held Mario accountable for the killing and its devastating impact on her entire family. She continued contact with him and urged him to 
take responsibility to make something good of his life, investing herself in his rehabilitation. As she later said, "He came into our life through an act of violence, but now he's in my heart. ... There's no way to bring back my son, but here's a life with potential that I don't want to waste."

Although Mr. Young did not take the path of forgiveness to the extent his wife had, crucially for their relationship, he respected her way of healing (Worthington \& Scherer, 2004). He forged his own transcendent path through community action. He took leadership in an organization to stop gun violence and worked tirelessly so that other families would not suffer such a tragedy. His wife later joined in those efforts, both finding that their activism furthered their own healing, yielding more energy to devote to their children's recovery.

The priest accompanied Mario's mother to his sentencing hearing "to sit at her side to give her courage." When Mr. Young arrived, the priest introduced them. Although she spoke no English, he saw the sorrow in her eyes for his loss and he embraced her, realizing that they both had lost their sons: his to a grave and hers to prison.

Families of victims - and those of offenders - are in need of ongoing support and advocacy. Most are better able to go on with their lives when they feel that justice has been served. Yet, many experience further trauma in lengthy, convoluted processes in the criminal justice system. Families of offenders too often face social condemnation, isolation, and neglect. As seen in the case above, the priest's bridging of the two families transcended barriers and fostered mutual compassion. On the anniversary of the murder, he invited both families to join him for dinner and prayers, which furthered their healing process.

Key processes in resilience, as outlined in the framework above, are evident in this remarkable case. Gradually, over many months, the Youngs - and Mario - found the determination to "master the possible": directing energies to forge some good out of the tragedy and to prevent future violence. Most significant was the power in tapping relational connections and spiritual resources - through faith beliefs and the involvement of clergy and congregations, and new purpose through community activism. These resources, long neglected in the mental health field, can be vital pathways in resilience.

\section{TRAUMATIC LOSS IN MAJOR DISASTERS}

Major disasters, both natural and human-caused, produce widespread disruption and loss for families and communities (Erikson, 1976). As one mother put it, "It's a cascade of sorrows." The pile-up effect of multiple losses, dislocations, and adaptational challenges can be overwhelming. It is particularly distressing for those who could not save those they cared about most. One man despaired that he had been unable to hold onto his disabled wife as they fled their home in rising floodwaters. When asked what helps him keep going, he replied, "It's her inspiration. Her last words to me were 'Take care of the kids and grandkids.' It's hard every minute, every day, but I can do it; her voice and her spirit give me the courage and determination."

Each survivor's experience is unique in sources of suffering and resilience. Counselors and other professionals can help to heal emotional wounds by understanding the particular impact and meaning of a traumatic loss situation and repairing fractured relationships, as in the following case. 
Many months after Hurricane Katrina floodwaters inundated a coastal community, a teacher in a nearby town found a 12-year-old boy sleeping in the streets, alone in his suffering. When asked to describe what had happened, he told her he had been approaching his house with his father when they saw his mother carried off in the flood surge. His father yelled at him to swim out and save her, but he stood frozen in place as his father berated him. Afterward, he ran away and had not seen his family since. He was too ashamed to tell his father he didn't know how to swim. He couldn't forgive himself for not saving his mother's life. He was still reluctant to visit his father, only a town away, but agreed to go with the counselor to see his uncle. Upon hearing the account, his uncle reassured him that the floodwaters that day were too strong for even a good swimmer to save the many lives that were lost. He added that he knew that the father could not swim, which was why, in his own helplessness, he had turned to his son with such desperation. The uncle took the boy in and arranged a reunion of father and son, beginning their healing from that tragic day.

As attention goes to bereaved families, survivors of a trauma can face a lonely road ahead. After a school fire killed many children, one girl who survived became depressed when everyone kept telling her how brave and lucky she was. No one asked about her experience, and she never revealed her deep shame: how in panic she had clawed her way through, stepping over classmates, to reach the window to jump. Another girl, who suffered spinal injuries when she jumped, was welcomed home from the hospital as a hero by friends and neighbors. However, most later avoided contact, uncomfortable in seeing her injuries and their reminder of the tragedy. Another survivor was pained when people consoled the bereaved families by saying that God had taken his special angels: What did it mean that God hadn't chosen her? Multifamily and community group sessions can provide a supportive context to share and assuage such concerns.

\section{Pathways in Recovery and Resilience}

Recent research underscores the importance of early intervention for those who have suffered trauma and traumatic loss (Litz, 2004). Relieving acute distress and mobilizing resources for recovery can be crucial in preventing more serious and chronic symptoms of PTSD. However, we should be wary of a "quick fix." Crisis intervention can be immensely helpful in providing initial information and support. However, some debriefing programs originally designed for crisis workers (e.g., Critical Incident Stress Debriefing; Mitchell \& Everly, 2003) have been found to be unhelpful and, in many cases, to increase suffering when applied in a one-session format with survivors in the immediate aftermath of a mass trauma event (Emmerik, Kamphuis, Hulsbosch, \& Emmelkamp, 2002). Suffering can be exacerbated by a narrow focus on individual trauma symptoms; by heightening worry that common trauma reactions are an early sign of PTSD, a psychiatric disorder; and by opening up intense, overwhelming, and painful memories and feelings, including helplessness and rage. It is crucial (1) to normalize and contextualize distress, (2) to draw out strengths and active coping strategies for empowerment, (3) to offer follow-up sessions and mental health services for those in severe or persistent distress, and (4) to mobilize family and social support for ongoing recovery.

The following facilitator guidelines are useful for early intervention in family or multifamily group sessions with those affected by traumatic loss. 
(1) Start with grounding in their personal identity, family, community, cultural, and spiritual connections.

(2) Invite members to share a few aspects of their crisis experience that stood out for them. Offer acknowledgment and compassionate witnessing of recent and ongoing crises, losses, hardships, or injustices that they have suffered.

(3) Draw out and affirm their strengths and potential in endurance and coping efforts, such as courage, perseverance, and mutual support in weathering hardships.

(4) Facilitate shared meaning making and mastery. Shift focus from what has happened to them to what they can do about their situation (from helplessness and victimization to active initiative and empowerment). Shift from a global sense of despair and immobilization to a hopeful outlook and manageable steps of progress.

(5) Identify sources of resilience to tap into important connections in their lives (link to those noted above) as lifelines in their recovery process, such as their ethnic heritage or religious community.

(6) Identify personal, relational, and spiritual resources that they, or their families of origin, drew on in past times of adversity and how they might be helpful now. For instance, a family may take pride in their "can-do" spirit in overcoming past hardship, or share strong faith that God will see them through to better days.

As studies of resilience amply document, in struggling to make meaning, in reaching out to others, and in active coping efforts, people tap resources that they may not have drawn on otherwise, and gain new abilities and perspective on life.

Families, teachers, counselors, and other workers find journals and artwork especially helpful with children. One program designed for use in disaster situations to facilitate meaning making, emotional expression, and active coping uses activity books to help children to express their experience of both suffering and resilience (Kliman, Oklan, Wolfe, \& Kliman, 2005). For instance, in "My Hurricane Katrina Story," drawing and word activities helped children to remember, document, and integrate not only the sad, bad, and scary parts, but also the helpful, brave, and good things that people did. In journal format, older children could describe what they learned; what would be helpful now; and things that they, their families, and their community could do to rebuild and be prepared for another hurricane. Such tasks foster key processes for resilience outlined in the framework above.

A disaster can reactivate past trauma but also offer opportunities for further healing. Families of the victims of a terrorist-caused plane crash over Lockerbie, Scotland, found their pain revived by another plane crash 8 years later - as one father described it, "like a scab torn off a deep wound." Yet many of those families came forward and offered support to the surviving families, finding that their assistance furthered their own long-term recovery as well.

The long and varied pathways in healing emotionally and rebuilding lives require the flexible availability of professionals and the support of kin and social networks over many months, and even years. In efforts to prevent and treat long-term posttraumatic stress complications, it is crucial to attend to the significant losses suffered and to facilitate the four tasks in adaptation to loss (outlined above). This will require pacing over time and weaving back and forth to address emotional grief work, meaning making, immediate practical challenges, and future directions. Survivors 
frequently note that there were times when they suffered so deeply, they didn't know if they could face another day, or felt that life no longer had meaning. In the immediate wake of traumatic loss, some families may be so overwhelmed by practical demands that members suppress emotional needs. They may not seek counseling until months later, after initial social support wanes and the full impact of losses is felt or symptoms of distress intensify.

The sadness of all that was lost is compounded when former lives can't be restored. Meaning making and recovery involve a struggle to understand what has been shattered, how to build new lives, and how to prevent future tragedy. As in an earthquake, we need to learn what vulnerabilities in structures contributed to their collapse, but we can learn even more from those structures that withstood such damage.

\section{Multisystemic Approaches to Recovery and Resilience}

In a humanitarian crisis, multisystemic approaches, with the active participation of local residents, facilitate both family and community resilience (Landau \& Saul, 2004). Community-based coordinated efforts involving local and national agencies and, where needed, international assistance, are essential to meet the challenges. Major disasters that disrupt family systems, work organizations, and community structures and services are most debilitating because they may lead to community fragmentation, conflict, and destabilization. Unresponsiveness by larger systems compounds the traumatic impact.

Multisystemic resilience-oriented approaches draw on and expand individual, family, and community resources that are critical components of recovery (Ungar, 2005). Landau's framework, grounded in disaster recovery experiences in many parts of the world, identifies and links these resources to create a matrix of healing. Natural leadership within the community is encouraged, with professionals taking a consultative role. Family and community members with diverse skills, talents, and ages can contribute in different ways to the resilience of the community. The elderly bring memories and lessons of coping with past adversity, and the young renew the capacity for play and creativity. This approach can be highly effective in generating hope and long-term viability for the future.

With massive psychosocial trauma in major disasters, whether natural or human caused, Landau and Saul (2004) have found that community resilience encompasses the following four themes: (1) Build community and enhance social connectedness as a foundation for recovery by strengthening the system of social support, coalition building, and information and resource sharing. (2) Participate in collective storytelling and validation of the trauma and response, with the emerging story broad enough to encompass the many varying experiences. (3) Reestablish the rhythms and routines of life and engage in collective healing rituals. (4) Arrive at a positive vision of the future with renewed hope. These themes echo the key processes in resilience described above in belief systems, organizational patterns, and communication processes.

In the aftermath of the devastation of Hurricanes Katrina and Rita on the coasts of Louisiana and Mississippi in 2005, the abysmal failure of government rescue and recovery efforts compounded the trauma, suffering, and chaotic displacement of residents. As too often occurs in a major disaster (Norris \& Alegria, 2005), those most affected - and most neglected - were those most vulnerable, especially people of color, those with limited means, the elderly, and those with serious health problems. Shockingly, many bodies 
remained unattended, prolonging the agony of families waiting to claim their loved ones and bury them with dignity. For disaster preparedness and recovery, the utmost importance of federal, state, and local emergency planning, coordination, communication, and follow-through cannot be overemphasized.

\section{TRAUMATIC LOSSES IN WAR, GENOCIDE, AND REFUGEE EXPERIENCE}

In our times, we've seen the vast human toll and devastation wrought by war, violent ethnic, tribal, religious, and political conflicts, and genocidal campaigns in many parts of the world. Family members may be forcibly separated, kidnapped, or made to witness brutal killing or abuse of loved ones; young boys are pressed into combat and girls sold in sex trafficking. Violence, in all forms, can fuel unending cycles of hatred and retaliation, with long-lasting multigenerational effects (Weingarten, 2004). The South African experiment in Truth and Reconciliation, through public accountability, remorse, and forgiveness, has offered a rehumanizing model for societal transformation to other regions in conflict (Gobodo-Madikizela, 2002; Sluzki, 2003).

The comfort and security provided by warm, caring relationships is especially critical in withstanding trauma events, which induce social and personal uprooting, family disruption, separation and loss, mental and physical suffering, and vast social change (Gourevitch, 1998; Hernández, 2002; Weine, 1999). In situations of complex, persistent trauma, the multiple losses and ongoing threats can be overwhelming. The security provided by families in war zones is crucial in buffering trauma (Garbarino, Kostelny, \& Dubrow, 1991). In evacuation, children and vulnerable family members fare best when able to stay together or in regular contact with kin.

\section{Resilience-Oriented Approach}

Refugee families face a myriad of challenges: overcoming experiences of physical and psychosocial trauma and loss, navigating disruptive transitions and further losses in migration, and adapting to a new culture and way of life (Mock, 1998). Many are forced to leave their homeland and seek asylum to escape persecution. Others are involuntarily displaced because of harsh conditions wrought by war, ethnic conflict, or environmental disasters. Those in refugee camps may be trapped for years or even decades. Experiences of starvation, torture, rape, imprisonment, and dehumanizing treatment or conditions are all too common. Many have suffered multiple traumatic losses of loved ones, homes, and communities and have witnessed brutal atrocities (Kamya, 2004; Mollica, 2004). In migration to a safe haven in another country, they often experience a profound loss of their social network and cultural roots, and experience a sense of homelessness between two worlds, belonging to neither (Falicov, 2003). Ongoing adaptational stressors - finding living quarters, jobs, health care, and schools; surmounting language barriers; navigating immigration laws; learning social rules and customs; experiencing discrimination and the loss of identity and status-compound the difficulty, with pile-up effects over time. Survivor guilt and worries about loved ones left behind can add to suffering. Marital and intergenerational tensions are intensified by past trauma.

A project developed by the Chicago Center for Family Health in collaboration with the Center on Genocide, Psychiatry, and Witnessing at the University of Illinois demonstrates the value of a community-based family resilience approach with refugees (Walsh, 2006; Weine et al., 2004). In 1998-1999, we developed multifamily groups 
for Bosnian and Kosovar refugees who had suffered losses of loved ones, homes, and communities as a result of the Serbian campaign of "ethnic cleansing." Our family resilience approach was sought out because many refugees were suffering from trauma and losses but were not using mental health services, which they viewed as pathologizing in the PTSD label and narrow focus on individual symptoms. Our approach countered the stigma and shame as it mobilized families to foster recovery and adaptation.

The program, called CAFES for Bosnian families and TAFES for Kosovar families (Coffee/Tea and Family Education \& Support), used a 9-week multifamily group format. Families readily participated because it tapped into the strong family-centered cultural values and was located in an accessible neighborhood storefront, where they felt comfortable. Offering a compassionate setting to share stories of suffering and struggle, it also affirmed family strengths and resources, such as their courage, endurance, and faith; strong kinship networks and deep concern for loved ones; and determination to rise above their tragedies to forge a new life. Efforts were encouraged to bridge cultures, sustain kinship ties, and gain a sense of belonging in both old and new worlds (Falicov, 2003). To foster collaboration and to develop local resources, facilitators from their community were trained to co-lead groups and were available as needs might arise. This approach was experienced as respectful and empowering.

The program's success led to an ongoing project to develop community-based, resilience-oriented, family-centered training and services in Kosovo to foster recovery in the war-torn region (Rolland \& Weine, 2000). With varied family therapy approaches, the consultants all shared a multisystemic, resilience-oriented metaframework and encouraged adaptation to fit local culture. In bearing witness to atrocities suffered, they also highlighted resources in family belief systems, organization, and communication processes. Islamic religion and the role of models and mentors were powerful wellsprings in resilience. One family drew strength from the mother's faith in God and her courage in carrying on after witnessing the murder of her husband and sons. An uncle shared stories with his nephews of the strong leadership and bravery of their deceased father and grandfather to inspire their best efforts for the future. In many families, strong cohesiveness and adaptive role flexibility enabled members to assume new responsibilities to fill in missing functions. Although their grief was immense, their resilience was remarkable (Becker, Sargent, \& Rolland, 2000). Recognizing the long-term challenges in recovery, Internet contact, periodic return trainings, and new collaborative projects have addressed emerging needs.

\section{TRAUMATIC LOSS IN TERRORISM}

In this age of widespread terrorism, the world has become more volatile and uncertain. With the terrorist attacks of September 11, 2001, Americans experienced the shocking loss of their worldview as safe, predictable, and just. Others in many parts of the world have gradually come to cope with terrorism (Malkinson, Rubin, \& Witztum, 2005). The trauma in the United States was intensified by the utter unpredictability and incomprehensibility of the events. In this sudden loss of the assumptive world, illusions of invulnerability were shattered and a palpable sense of the precariousness of life was widely experienced (Walsh, 2002). Yet this was not the first attack in the United States; valuable lessons can be learned from the experience of the Oklahoma City bombing. How a community responds can make all the difference for recovery. 


\section{Lessons From the Oklahoma City Bombing: Community Response and Resilience}

A remarkable demonstration of community resilience emerged after the 1995 Oklahoma City bombing of the Murrah Federal Building (Sitterle \& Gurwitch, 1999). Amid the immediate chaos and suffering, local people came together in recovery initiatives, collaborating in outreach and organizational efforts. Thousands of professionals, volunteers, and rescue workers joined forces for effective crisis intervention for those in need and a strong support system for responders.

One notable program was the creation of the Compassion Center in a local church, where hundreds of families gathered for information about their loved ones. A multiagency effort was quickly organized to provide accurate information about rescue efforts, to facilitate identification, and to offer emotional support. The center coordinated multiple emergency and community organizations to respond to the many needs of survivors. Mental health services provided a safe environment for families to process information in a respectful way, to share their suffering, and to regain a sense of order, predictability, and structure in their lives.

Rituals were important in fostering unity and healing. They channeled grief and terror into meaningful and life-affirming activities and instilled faith in the long healing process. Informal memorials and offerings were created at the bombing site and around the "survivor tree," which had been damaged but not destroyed by the blast. An official memorial service and later remembrance events paid tribute to all those whose lives were lost.

Case studies of group recovery (Zinner \& Williams, 1999) have found that the grief experience may become a developmental crisis or a growthful opportunity for a community. Catastrophic events, traumatic loss, and suffering can lead to a breakdown in community morale and stagnate future development. In Oklahoma City, it strengthened resolve to rebound and propelled the community into new areas of growth. Learned resourcefulness, rather than helplessness, marked their recovery. Community members stepped forward to fill many roles, providing mutual benefit by helping others and gaining an empowering sense of efficacy. It was this process of collaboration, meaning making, and mastering at least some part of the traumatic experience that promoted resilience.

\section{Family and Community Resilience in Response to World Trade Center Attacks}

The terrorist attacks on September 11, 2001, had widespread ripple effects. A few notable illustrations are offered here to reveal the resilience possible when families and communities rally in the wake of tragedy.

In New York, thousands gathered at the site of the attacks to organize support services, aid in recovery, and clean up. Rituals were vitally important in healing (Imber-Black, 2003). Numerous remembrance events took place in candlelight vigils, community gatherings, and places of worship. Caring responses poured in from strangers around the nation and the world. The Oklahoma City community offered assistance to grieving families and sent a huge shipment of teddy bears to comfort those awaiting news of their loved ones.

Over time, bereaved families organized into advocacy groups, such as "the Jersey Moms" and "Voices of September 11" to provide resources and support. They spoke out in public arenas and pressed for an independent commission to understand how the attacks came about and might have been prevented, and to draw up recommen- 
dations to avert and prepare for any future threat. Their concerted efforts to clarify and make meaning of the crisis event, draw lessons from it, and take proactive steps are core processes in family and community resilience.

As Landau and Saul (2004) note, community members are a natural support system with many advantages over outside providers. They have well-developed relationship networks and access to local knowledge of resources and vulnerable populations. Often they are already engaged in positive social processes that build solidarity, such as community associations and volunteer groups. Efforts that are driven by local priorities are generally more successful than programs imported by outsiders. Community members with investment in their future are more likely to sustain activities after initial funding for a crisis dries up.

The Lower Manhattan Community Recovery Project. In neighborhoods directly affected by the terrorist attack, mental health professionals initially focused on potential pathology in children, with little place for parents to discuss their concerns. Schools were closed and families were displaced from their homes for several months. Parents became distressed on reentry, when children were to return to their schools where they had experienced the trauma. Saul and colleagues organized a neighborhood-based program, involving local agencies and residents, to facilitate child, family, and community resilience (Landau \& Saul, 2004). Multifamily groups and networks of parents, teachers, counselors, and school staff were set up as a resource to share experiences, respond to children's concerns, provide mutual support, and mobilize concerted action in recovery efforts. Varied reactions were normalized and a framework was offered, identifying common phases in disaster recovery. The process of community connectedness provided a matrix of healing and support along with sound reality testing. These groups developed into ongoing forums. A community-needs assessment led to the creation of a neighborhood resource center, a public space to gather and share ideas and creativity. They formed a disaster preparedness initiative and developed such projects as a video narrative archive, a theater of witness project, a community Web site, a computer education program for seniors, and art and music projects, with long-lasting positive impact.

Family Meetings as Community Intervention for Ambiguous Loss. Another team of systems-oriented therapists, co-led by Boss (Boss, Beaulieu, Wieling, Turner, \& LaCruz, 2003), worked with families of World Trade Center labor union workers who were missing after the attacks. Multifamily group meetings were held in the union hall, where families felt comfortable. Intervention teams were multilingual, multiracial, and attuned to the cultural diversity of families. Group leaders helped families share anguishing experiences and communicated their basic premise: When a loved one remains missing, it is the situation of ambiguous loss that is abnormal, not distressed family members. The group interactions and mutual support were empowering, with several widows taking on leadership roles over time.

\section{TRAUMATIC LOSS: CHALLENGES AND OPPORTUNITIES}

Traumatic losses reverberate throughout families and their communities; in turn, their response can help or hinder recovery. Tragic events can awaken us to what really matters in life and inspire us to redefine our identity, to reorder our priorities, and to take initiative in caring actions to benefit others. Communities have shown that they 
could endure the worst forms of suffering and loss, and with time and concerted effort, rebuild and even grow stronger. After a fire destroyed the city of Chicago in 1871, forward-looking community leaders gathered the world's greatest city planners and architects to rebuild it, literally out of the ashes. That resilient response to tragedy made possible the transformation of the skyline and lakefront with innovative skyscrapers and vast public parks. In our times, we will need strong leadership, investment, and collaborative efforts to rebuild communities devastated by major disasters.

As clinicians, our own resilience is tested in work with traumatic loss. Compassion fatigue is common (Figley, 2002) in witnessing the many stories of trauma and in experiencing our clients' ongoing distress. It is especially challenging for rescue workers and professionals who, with their loved ones, have been directly affected by the event or continue to be in harm's way. It is helpful to draw strength from our families, friends, communities, and spiritual resources, just as it is for those we serve. We can also reap benefits in our professional and personal lives, as we draw inspiration and insights from the remarkable resilience that so many families forge as they gather strength to live and love fully after devastating loss (Hernández, Gangsei, \& Engstrom, 2007).

Mental health professionals cannot heal all the wounds suffered in tragic loss and humanitarian crises. What we can do is create a safe haven for family and community members to share both deep pain and positive strivings. Of value is our compassionate witnessing (Weingarten, 2004) for their suffering and struggle, and our admiration for their strengths and endurance. We can encourage their mutual support and active strategies to meet their challenges. We can rekindle their hopes and dreams for a better future, support their best efforts and actions, and mobilize resources toward their aims. Multisystemic, resilience-oriented practice approaches help families and communities expand their vision of what is possible through collaboration, not only to survive trauma and loss but also to regain their spirit to thrive.

\section{REFERENCES}

American Psychiatric Association. (2000). Diagnostic and statistical manual of mental disorders (4th ed.). Washington, DC: Author.

Becker, C., Sargent, J., \& Rolland, J. (2000). Kosovar Family Professional Educational Collaborative. American Family Therapy Academy Newsletter, 80, 26-30.

Boss, P. (1999). Ambiguous loss: Learning to live with unresolved grief. Cambridge, MA: Harvard University Press.

Boss, P., Beaulieu, L., Wieling, E., Turner, W., \& LaCruz, S. (2003). Healing loss, ambiguity, and trauma: A community-based intervention with families of union workers missing after the 9 / 11 attack in New York City. Journal of Marital and Family Therapy, 29, 455-467.

Calhoun, L.G., \& Tedeschi, R.G. (1999). Facilitating posttraumatic growth: A clinician's guide. Mahwah, NJ: Erlbaum.

Calhoun, L.G., \& Tedeschi, R.G. (Eds.). (2006). Handbook of posttraumatic growth: Research and practice. Mahwah, NJ: Erlbaum.

Catherall, D.R. (1992). Back from the brink: A family guide to overcoming traumatic stress. New York: Bantam Books.

Catherall, D.R. (Ed.). (2004). Handbook of stress, trauma, and the family. New York: BrunnerRoutledge.

Danieli, Y. (1985). The treatment and prevention of long-term effects and intergenerational transmission of victimization: A lesson from Holocaust survivors and their children. In C.R. Figley (Ed.), Trauma and its wake (pp. 295-313). New York: Brunner/Mazel. 
Denborough, D. (Ed.). (2006). Trauma Narratives responses to traumatic experiences. Adelaide, Australia: Dulwich Centre Publications.

Doka, K. (2002). Disenfranchised grief. Champaign, IL: Research Press.

Emmerik, A., Kamphuis, A., Hulsbosch, P., \& Emmelkamp, P. (2002). Single-session debriefing after psychological trauma: A meta-analysis. Lancet, 360, 766-771.

Erikson, K.T. (1976). Everything in its path: Destruction of community in the Buffalo Creek flood. New York: Simon and Schuster.

Falicov, C.J. (2003). Immigrant family processes. In F. Walsh (Ed.), Normal family processes (3rd ed., pp. 280-300). New York: Guilford Press.

Figley, C.R. (1998). The traumatology of grieving. San Francisco: Jossey-Bass.

Figley, C.R. (Ed.). (2002). Treating compassion fatigue. New York: Brunner/Rutledge.

Figley, C., \& McCubbin, H. (Eds.). (1983). Stress and the family: Coping with catastrophe. New York: Brunner-Mazel.

Frankl, V. (1984). Man's search for meaning. New York: Simon and Schuster. (Original work published 1946).

Garbarino, J. (1997). Raising children in a socially toxic environment. San Francisco: JosseyBass.

Garbarino, J., Kostelny, K., \& Dubrow, N. (1991). No place to be a child: Growing up in a war zone. Lexington, MA: Lexington Books.

Gobodo-Madikizela, P. (2002). Remorse, forgiveness, and rehumanization: Stories from South Africa. Journal of Humanistic Psychology, 42, 7-32.

Gourevitch, P. (1998). We wish to inform you that tomorrow we will be killed with our families: Stories from Rwanda. New York: Picador.

Hernández, P. (2002). Resilience in families and communities: Latin American contributions from the psychology of liberation. Journal of Counseling and Therapy for Couples and Families, 10, 334-343.

Hernández, P., Gangsei, D., \& Engstrom, D. (2007). Vicarious resilience: A new concept in work with those who survive trauma. Family Process, 46, 229-242.

Hill, R. (1949). Families under stress. New York: Harper.

Imber-Black, E. (1988). Families and larger systems. New York: Guilford Press.

Imber-Black, E. (2003). September 11: Rituals of healing and transformation. In E. ImberBlack, J. Roberts, \& R. Whiting (Eds.), Rituals in families and family therapy (2nd ed., pp. 333-344). New York: Norton.

Imber-Black, E., Roberts, J., \& Whiting, R. (Eds.). (2003). Rituals in families and family therapy (2nd ed.). New York: Norton.

International Society for Traumatic Stress Studies. (Nov. 4-7, 2006). The psychobiology of trauma and resilience across the lifespan. Proceedings, 22nd Annual Meeting. www.istss.org

Janoff-Bulman, R. (1992). Shattered assumptions: Towards a new psychology of trauma. New York: Free Press.

Kamya, H. (2004). The impact of war on children and families: Their stories, my stories. AFTA Monograph Series, 1, 29-32.

Kauffman, J. (Ed.). (2002). Loss of the assumptive world: A theory of traumatic loss. New York: Brunner-Routledge.

Kliman, G., Oklan, E., Wolfe, H., \& Kliman, J. (2005). My Hurricane Katrina workbook. San Francisco: The Children's Psychological Health Center.

Landau, J., \& Saul, J. (2004). Family and community resilience in response to major disaster. In F. Walsh \& M. McGoldrick (Eds.), Living beyond loss: Death in the family (2nd ed., pp. 285309). New York: Norton.

Lattanzi-Licht, M., \& Doka, K. (Eds.). (2003). Living with grief: Coping with public tragedy. Washington, DC: Hospice Foundation of America.

Litz, B. (2004). Early intervention for trauma and traumatic loss. New York: Guilford Press.

Fam. Proc., Vol. 46, June, 2007 
Malkinson, R., Rubin, S., \& Witztum, E. (2005). Terror, trauma, and bereavement: Implications for theory and therapy. In Y. Danieli, D. Brom, \& J. Sills (Eds.), The trauma of terrorism: Sharing knowledge and shared care: An international handbook (pp. 467-481). New York: Haworth.

McFarlane, A., \& Yahuda, R. (1996). Resilience, vulnerability, and the course of posttraumatic reactions. In B. van der Kolk, A. McFarlane, \& L. Weisaeth (Eds.), Traumatic stress: The effects of overwhelming stress on mind, body, and society (pp. 155-181). New York: Guilford Press.

Mitchell, J.T., \& Everly, G.S. (2003). Critical Incident Stress Debriefing: An operations manual for CISD, defusing, and other group crisis intervention services (4th ed.). Ellicott City, MD: Chevron.

Mock, M. (1998). Clinical reflections on refugee families: Transforming crises into opportunities. In M. McGoldrick (Ed.), Re-visioning family therapy (pp. 347-359). New York: Guilford.

Mollica, R. (2004). Surviving torture. New England Journal of Medicine, 35, 5-7.

Nadeau, J.W. (2001). Family construction of meaning. In R. Neimeyer (Ed.), Meaning reconstruction and the experience of loss (pp. 95-111). Washington, DC: American Psychological Association.

Neimeyer, R.A. (Ed.). (2001). Meaning reconstruction and the experience of loss. Washington, DC: American Psychological Association.

Norris, F.H. (2002). 60,000 disaster victims speak: Part 1. An empirical review of the empirical literature, 1981-2001. Psychiatry: Interpersonal and Biological Processes, 65, 207-239.

Norris, F.H., \& Alegria, M. (2005). Mental health care for ethnic minority individuals and communities in the aftermath of disasters and mass violence. CNS Spectrums, 10, 132-140.

Perry, A., \& Rolland, J. (1999). Spirituality expressed in community action and social justice. In F. Walsh (Ed.), Spiritual resources in family therapy (pp. 272-292). New York: Guilford Press.

Rando, T. (1993). Treatment of complicated mourning. Champaign, IL: Research Press.

Rolland, J.S., \& Weine, S. (2000). Kosovar Family Professional Educational Collaborative. American Family Therapy Academy Newsletter, 79, 34-35.

Rutter, M. (1999). Resilience concepts and findings: Implications for family therapy. Journal of Family Therapy, 21, 119-144.

Shefsky, J. (2000). A justice that heals [Documentary film]. Chicago: WTTW, Windows of the World Communications.

Sitterle, K.A., \& Gurwitch, R.H. (1999). The terrorist bombing in Oklahoma City. In E.S. Zinner \& M.B. Williams (Eds.), When a community weeps (pp. 161-189). New York: Brunner/Mazel.

Sluzki, C.E. (2003). The process toward reconciliation. In A. Chayes \& M. Minow (Eds.), Imagine coexistence: Restoring humanity after violent ethnic conflict (pp. 21-30). San Francisco: Jossey-Bass.

Speck, R. (2003). Social network intervention. In G.P. Sholevar \& L.D. Schwoeri (Eds.), Textbook of family and couples therapy (pp. 193-201). Washington, DC: American Psychiatric Press.

Stroebe, M., \& Schut, H. (2001). Meaning making in the dual process model of coping and bereavement. In R. Neimeyer (Ed.), Meaning reconstruction in the experience of loss (pp. 5573). Washington, DC: American Psychological Association.

Tedeschi, R.G., \& Calhoun, L.G. (1996). The Posttraumatic Growth Inventory: Measuring the positive legacy of trauma. Journal of Traumatic Stress, 9, 455-471.

Terkel, S. (2002). Will the circle be unbroken? Reflections on death, rebirth, and the hunger for a faith. New York: Ballantine Books.

Ungar, M. (Ed.). (2005). Handbook of working with children and youth: Pathways to resilience across cultures and contexts. Thousand Oaks, CA: Sage.

van der Kolk, B.A., McFarlane, A.C., \& Weisaeth, L. (Eds.). (1996). Traumatic stress: The effects of overwhelming experience on mind, body, and society. New York: Guilford Press. 
Walsh, F. (2002). Bouncing forward: Resilience in the aftermath of September 11. Family Process, 41, 34-36.

Walsh, F. (2003). Family resilience: A framework for clinical practice. Family Process, 42, 1-18.

Walsh, F. (2004). Spirituality, death, and loss. In F. Walsh \& M. McGoldrick (Eds.), Living beyond loss: Death in the family (2nd ed., pp. 182-210). New York: Norton.

Walsh, F. (2006). Strengthening family resilience (2nd ed.). New York: Guilford Press.

Walsh, F., \& McGoldrick, M. (2004). Loss and the family: A systemic perspective. In F. Walsh \& M. McGoldrick (Eds.), Living beyond loss: Death in the family (2nd ed, pp. 3-26). New York: Norton.

Webb, N.B. (Ed.). (2003). Mass trauma and violence: Helping families and children cope. New York: Guilford Press.

Weine, S. (1999). When history is a nightmare. New Brunswick, NJ: Rutgers University Press.

Weine, S., Muzurovic, N., Kulauzovic, Y., Besic, S., Lezic, A., Mujagic, A., et al. (2004). Family consequences of refugee trauma. Family Process 43, 147-160.

Weingarten, K. (2003). Common shock: Witnessing violence every day: How we are harmed, how we can heal. New York: Dutton.

Weingarten, K. (2004). Witnessing the effects of political violence in families: Mechanisms of intergenerational transmission of trauma and clinical interventions. Journal of Marital and Family Therapy, 30, 45-59.

World Health Organization. (1972). International statistical classification of diseases and related health problems (10th ed.). Geneva, Switzerland: Author.

Worthington, E.L. Jr., \& Scherer, M. (2004). Forgiveness is an emotion-focused coping strategy that can reduce health risks and promote health resilience: Theory, review, and hypotheses. Psychology and Health, 19, 385-406.

Wortman, C., \& Silver, R. (1989). The myths of coping with loss. Journal of Counseling and Clinical Psychology, 57, 349-357.

Zinner, E.S., \& Williams, M.B. (Eds.). (1999). When a community weeps: Case studies in group survivorship. New York: Brunner/Mazel. 
